\title{
Serous Cystic Neoplasm: Do We Have to Wait Till It Causes Trouble?
}

Serous cystic neoplasm (SCN) of the pancreas is considered a benign tumor with almost no malignant potential. Most surgeons agree that asymptomatic SCN requires only regular observation. However, several complexities and interference with organ preservation during the operation, may develop when a huge symptomatic tumor is treated with surgery. So, the purpose of this study is to develop a potential management plan based on a literature review and by describing three recent cases of SCN of the pancreas. We suggest that SCNs be responded to with a timely and appropriate surgical intervention - before they require clinical attention.

Key Words: Serous cystadenoma, Symptomatic, Surgical treatment
Ho Kyoung Hwang, M.D. ${ }^{1,6,7}$, Young Eun Chung, M.D., Ph.D. ${ }^{2,6,7}$, Hyun Ki Kim, M.D., Ph.D. $3,6,7$, Jung Yub Park, M.D. Ph.D. ${ }^{4,6,7}$, Hye Jin Choi, M.D. ${ }^{5,6,7}$, Chang Moo Kang, M.D., ${ }^{1,6,7}$, Woo Jung Lee, M.D., Ph.D.,

Departments of ${ }^{1}$ Surgery, ${ }^{2}$ Radiology, ${ }^{3}$ Pathology, ${ }^{4}$ Internal Medicine, and ${ }^{5}$ Medical Oncology, Yonsei University College of Medicine, ${ }^{6}$ Pancreaticobiliary Cancer Clinic, Yonsei University Health System, ${ }^{7}$ Young Yonsei Pancreatic Tumor Study Group

\section{Corresponding Author}

Chang Moo Kang

Department of Surgery, Yonsei

University College of Medicine, 250, Seongsanno, Seodaemun-gu, Seoul, 120-752, Korea

Tel: +82-2-2228-2100

Fax: +82-2-313-8289

E-mail: cmkang@yuhs.ac

${ }^{*}$ This work was supported by a Korean Federation of Science and Technology Societies Grant funded by the Korean Government (Research project No.: E00023).

Received: 2011. 2. 1

Accepted: 2011. 4. 2

\section{Introduction}

Ten to 20 percent of pancreatic cysts are neoplastic cysts, and malignant cystic neoplasms account for about 1\% of malignant pancreatic tumors. ${ }^{1,2}$ Unlike mucinous cystic neoplasm or intraductal papillary mucinous neoplasm of the pancreas, pancreatic serous cystic neoplasm is 
Ho Kyoung Hwang, et al : Serous Cystic Neoplasm: Do We Have to Wait Till It Causes Trouble?

considered a benign tumor with almost no malignant potential. Only expectant management with serial follow-up need be provided, and surgery is not recommended in the absence of symptoms. Since, George et al. ${ }^{3}$ reported the first case of serous cystadenocarcinoma in 1989, only about 25 cases have been reported around the world. ${ }^{4}$

With the development of better socioeconomic conditions and of increasing concern for personal health, asymptomatic benign or borderline malignant cystic neoplasms of the pancreas are increasingly detected. ${ }^{5-7}$ In addition, experiences with pancreatectomy along with advances in surgical technique and perioperative management have reduced operative mortality following pancreatectomy to a level of general acceptance. ${ }^{8}$ Furthermore, minimally invasive (laparoscopic or robotic) pancreatec- tomy is currently available and can be safely performed, and it would also be beneficial in terms of quality of life. Taking these facts into consideration, what would be an appropriate way of managing serous cystic tumor of the pancreas? In this report, we present three recent cases of serous cystic neoplasm of the pancreas and suggest a potential management plan based on a literature review.

\section{Case Reports}

Case 1 was a female patient admitted to our hospital due to dyspnea and a palpable mass. An abdominal CT scan showed a huge pancreatic mass compressing adjacent vascular structures and intraabdominal organs (Fig. 1A). She underwent spleen-preserving subtotal distal pancreatec-
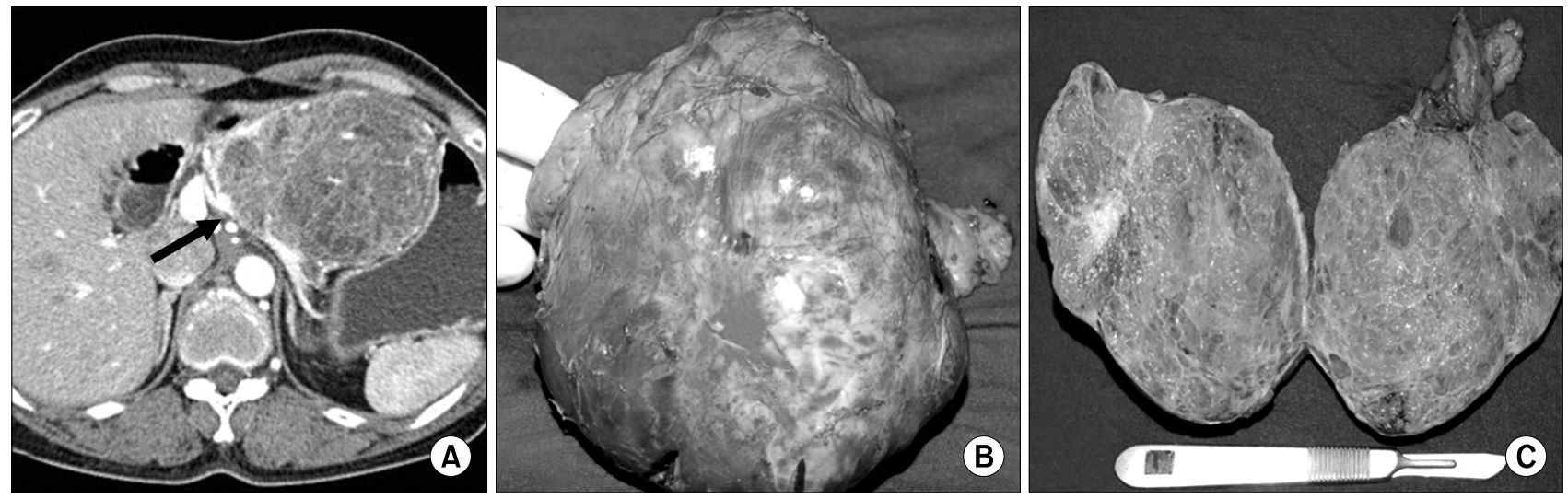

Fig. 1. (Case 1) A large tumor is compressing the adjacent splenic vein (arrow).
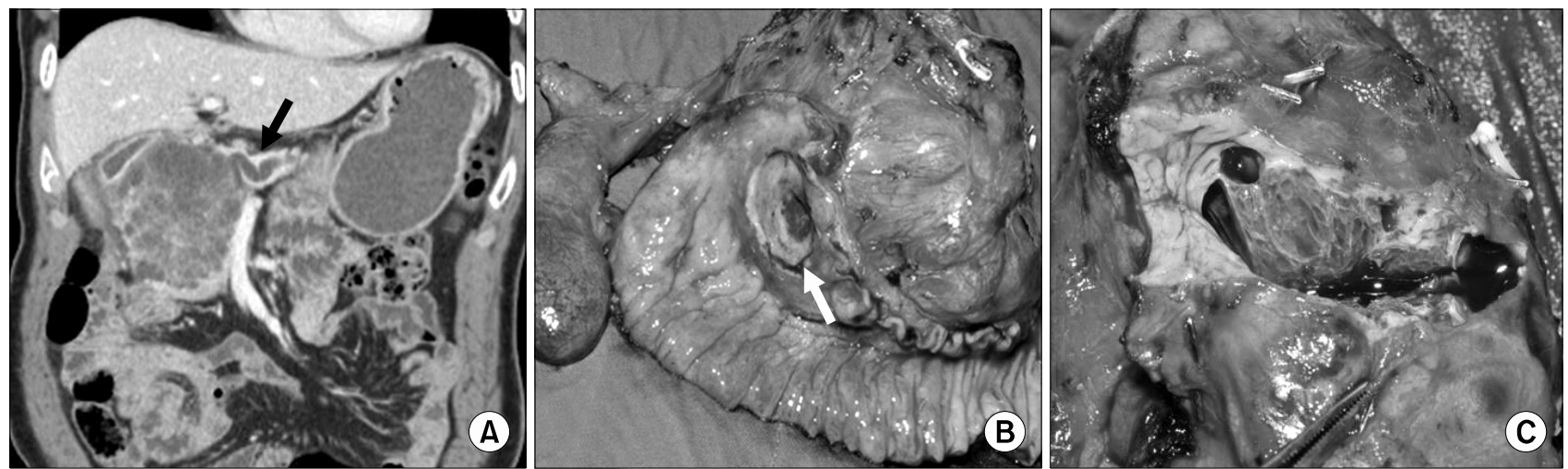

Fig. 2. (Case 2) Note dilatation of the distal pancreatic duct (A, arrow) and a huge duodenal ulcer (B, arrow). 
tomy with segmental resection of whole splenic vessels. The tumor was reported as a serous cystadenoma (Fig. 1B, C). In case 2, a patient had been followed up for a pancreatic serous cystic neoplasm over the last 5 years. At initial presentation, tumor size was about $4.5 \mathrm{~cm}$ without any symptoms. Recently, he developed abdominal pain, discomfort, and indigestion. Axial imaging found that the tumor had become enlarged, up to $8 \mathrm{~cm}$ in size, and caused dilation of the distal pancreatic duct (Fig. 2A). She underwent pancreatoduodenectomy. The tumor was abutting the gastroduodenal artery and superior mesenteric vein, but did not invade surrounding major vascular structures. Pathologic examination found a huge duodenal ulcer and an $8 \mathrm{~cm}$ sized serous cystadenoma without definitive invasive features (Fig. 2B, C).

In case 3, an incidental pancreatic tumor was found during evaluation of a woman's renal cyst (Fig. 3A). There were no symptoms related to the pathology of the pancreatic tail. After fully understanding the natural course of serous cystic neoplasm, she agreed to surgical extirpation. Robotic spleen-preserving distal pancreatectomy conserving both splenic vessels was performed (Fig. 3B). The pancreatic tumor was reported as a serous cystadenoma (Fig. 3C). All cases are summarized in Table 1.

\section{Discussion}

Most pancreatic serous cyst neoplasms are rare and asymptomatic, with a benign nature. However, the prevalence of cancer among serous cystic neoplasms is known to be about 3\%. ${ }^{9}$ According to a recent literature review of serous cystadenocarcinoma, ${ }^{4}$ the median age of patients is 68 years old (range, 52 85 years), and the median tumor size is $10 \mathrm{~cm}$ (range, 2.5 19 cm). This suggests that serous cystic neoplasm might eventually progress to large malignant tumors in the elderly when left without appropriate
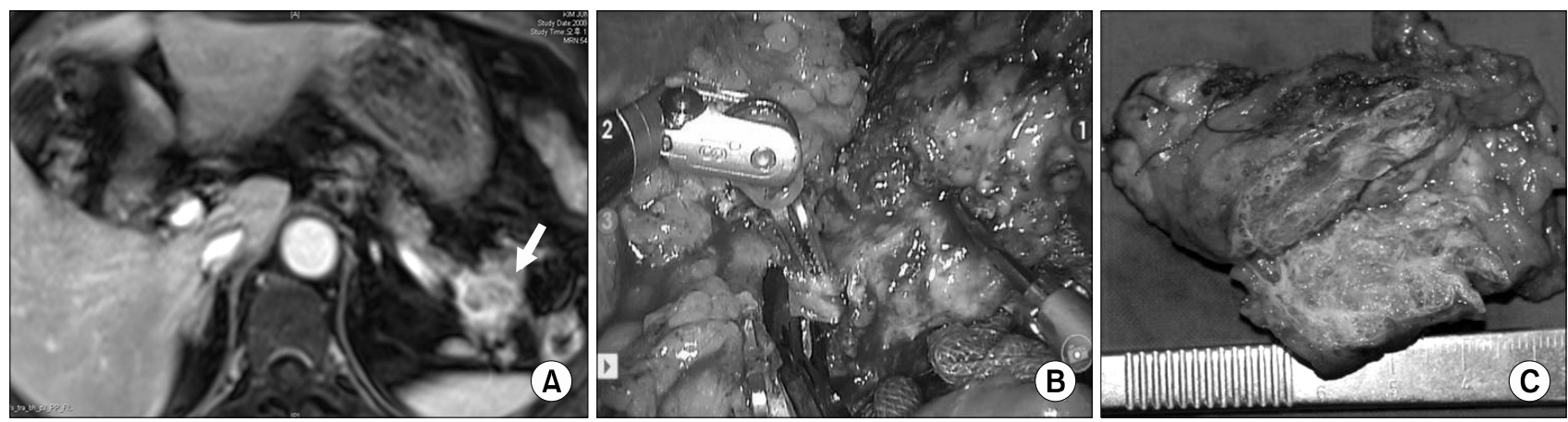

Fig. 3. (Case 3) An articulating surgical instrument facilitates fine dissection of small tributary vessels between splenic vessels and the distal pancreas (B).

Table 1. Patient presentations

\begin{tabular}{ccccccc}
\hline Case & Age & Gender & Symptom & Surgery & $\begin{array}{c}\text { Size } \\
(\mathrm{cm})\end{array}$ & Pathology \\
\hline 1 & 58 & $\mathrm{~F}$ & Palpable mass Dyspnea & SPDP* $^{*}$ with SRSA\&SV & 11 & SCA $^{\dagger}$ \\
2 & 75 & M & Abdominal pain Indigestion & PPPD $^{\S}$ & 8 & $\begin{array}{c}\text { SCA with pancreatic } \\
\text { duct dilation }\end{array}$ \\
3 & 65 & F & Incidental finding & Robotic SPDP & 3.2 & SCA \\
\hline
\end{tabular}

*SPDP=spleen preserving distal pancreatectomy; ${ }^{\dagger} \mathrm{SCA}=$ serous cystadenoma; ${ }^{\dagger}$ SRSA\&SV=segmental resection of splenic artery and vein; ${ }^{\S} \mathrm{PPPD}=$ pylorus-preserving pancreatoduodenectomy 


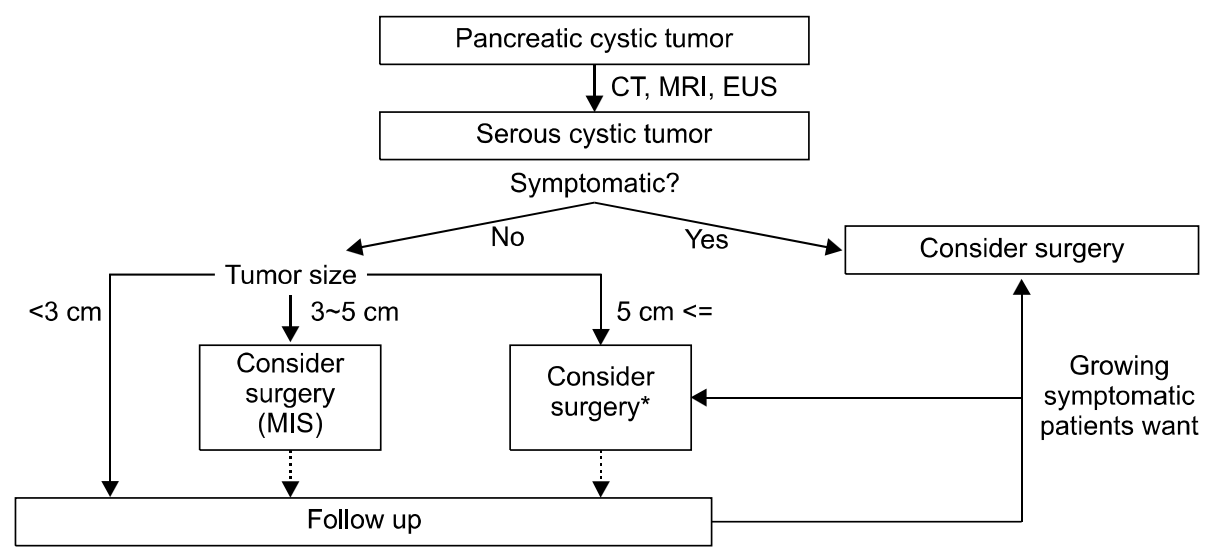

Fig. 4. Suggested approach to serous cystic tumor of the pancreas. MIS: minimally invasive surgery, *MIS may be chosen according to the surgeon's preference, experience, and skills.

treatment. In addition, Tseng et al. ${ }^{10}$ observed that serous cystic neoplasms smaller than $4 \mathrm{~cm}$ at presentation grow slowly (only about $0.12 \mathrm{~cm} /$ year), whereas those larger than $4 \mathrm{~cm}$ at presentation grow much faster $(1.98 \mathrm{~cm} /$ year $)$. They also reported that larger tumors were more likely to develop symptoms later, suggesting that the tumor biology may be different according to tumor size, and that a pancreatic serous cystic neoplasm aggressively transforms as it grows. In recent clinical practice, the strategy for asymptomatic small serous cystic neoplasm, which used to be a conditional observation of a periodic axial image study, needs to be reevaluated. In the past, higher morbidity and potential mortality following pancreatectomy was thought to be a great obstacle in applying a surgical approach to asymptomatic serous cystic neoplasms. However, recent advances in surgical techniques, experiences, and preoperative management have reduced operative morbidity and mortality to generally acceptable ranges. ${ }^{11}$ In particular, minimally invasive (laparoscopic and robotic) pancreatectomy can be safely performed these days. ${ }^{12,13}$ Long-term survival following successful pancreatectomy is highly expected in patients with benign and borderline malignant tumors. So, quality of life needs to be considered in choosing among surgical options.

Cases 1 and 2 are considered as clinical outcomes of conditional observations of asymptomatic serous cystic neoplasms. The patient in case 3 was treated with function-preserving, minimally invasive pancreatectomy. Considering that the natural course of serous cystic neoplasm is to become large and symptomatic or to undergo malignant degeneration, timely surgical intervention with either conventional open or minimally invasive surgery is a more reasonable strategy for current clinical practice. We suggest a strategy for managing serous cystic neoplasm of the pancreas (Fig. 4) based on our clinical experience and a literature review. While tumor size matters, a surgical approach with minimally invasive surgery needs to be considered, even in cases with asymptomatic small serous cystic neoplasms, as they may develop, cause symptoms, and become malignant (Fig. 2).

In summary, serous cystic neoplasm of the pancreas is rare but seems to be increasing due to easy access to medical care and improvements in pancreatic imaging. Based on a literature review and the cases presented here, the natural course of serous cystic neoplasm appears to be related to tumor size, symptoms and malignancy. Thus, we suggest timely and appropriate surgical intervention for SCNs before they require clinical attention.

\section{References}

1. Becker WF, Welsh RA, Pratt HS. Cystadenoma and cysta- 
denocarcinoma of the pancreas. Ann Surg 1965;161:845-863.

2. ReMine SG, Frey D, Rossi RL, Munson JL, Braasch JW. Cystic neoplasms of the pancreas. Arch Surg 1987;122:443-446.

3. George DH, Murphy F, Michalski R, Ulmer BG. Serous cystadenocarcinoma of the pancreas: a new entity? Am J Surg Pathol 1989;13:61-66.

4. King JC, Ng TT, White SC, Cortina G, Reber HA, Hines OJ. Pancreatic serous cystadenocarcinoma: a case report and review of the literature. J Gastrointest Surg 2009;13:1864 1868.

5. Fernández-del Castillo C, Targarona J, et al. Incidental pancreatic cysts: clinicopathologic characteristics and comparison with symptomatic patients. Arch Surg 2003;138:427-423.

6. Sahani D, Prasad S, Saini S, Mueller P. Cystic pancreatic neoplasms evaluation by $C T$ and magnetic resonance cholangiopancreatography. Gastrointest Endosc Clin N Am 2002;12: 657-672.

7. Yoon WJ, Lee JK, Lee KH, Ryu JK, Kim YT, Yoon YB. Cystic neoplasms of the exocrine pancreas: an update of a nationwide survey in Korea. Pancreas 2008;37:254-258.

8. Birkmeyer JD, Warshaw AL, Finlayson SR, Grove MR,
Tosteson AN. Relationship between hospital volume and late survival after pancreaticoduodenectomy. Surgery 1999;126: 178-183.

9. Strobel O, Z'graggen K, Schmitz-Winnenthal FH, et al. Risk of malignancy in serous cystic neoplasms of the pancreas. Digestion 2003;68:24-33.

10. Tseng JF, Warshaw AL, Sahani DV, Lauwers GY, Rattner DW, Fernandez-del Castillo C. Serous cystadenoma of the pancreas: tumor growth rates and recommendations for treatment. Ann Surg 2005;242:413-419.

11. Balcom JH 4th, Rattner DW, Warshaw AL, Chang Y, Fernandez-del Castillo C. Ten-year experience with 733 pancreatic resections: changing indications, older patients, and decreasing length of hospitalization. Arch Surg 2001;136: 391-398.

12. Røsok BI, Marangos IP, Kazaryan AM, et al. Single-centre experience of laparoscopic pancreatic surgery. $\mathrm{Br} J$ Surg 2010;97:902-909.

13. Giulianotti PC, Sbrana F, Bianco FM, et al. Robot-assisted laparoscopic pancreatic surgery: single-surgeon experience. Surg Endosc 2010;24:1646-1657. 